\title{
Energy-efficient architecture of industrial facilities associated with the desalination of sea water
}

\author{
Timur Gazizov ${ }^{1 \mathrm{a}}$, and Irina Melnikova ${ }^{1}$ \\ ${ }^{1}$ Moscow State University of Civil Engineering, 129337, Moscow, Russia
}

\begin{abstract}
The article offers an actual solution of a problem of drinking water shortage in the territory of the Crimean coast, in the city of Sudak, Autonomous Republic of Crimea, Russia. The project includes a development of energy-efficient architecture, its implementation in industrial facilities, such as stations for seawater desalination and an active use of alternative energy sources.
\end{abstract}

\section{Introduction}

Today there are industrial enterprises that are directly related to the functioning of cities and to existence of human society in them. For example, a modern city cannot exist without incineration plants, thermal power stations, treatment plants, etc. Such enterprises include plant for desalination of sea water. Especially necessity of uninterrupted operation of such enterprises increases in the case of industrial and natural disasters. Suffice it to recall the tragedy in Japan, 2011, when the regular major earthquake unbalanced a large part of the Japanese residential areas. What is particularly important - in the first days after the tragedy all bottled fresh water was sold out, even in areas that located far from the most affected places. Value of drinking water increases by tens and hundreds of times under such conditions. Today, fresh water in industrialized countries is worth more than oil even against the background of a peaceful and prosperous life in cities. More and more scientists tend to believe that no oil and gas, but clean fresh water will become a major problem of the XXI century. In arid regions of the world water was always number one and was the cause of many wars and armed conflicts in the territories, which was poor of natural fresh water resources. A good example of such conflict is the "War for water 1964". Thus, engineering of such objects, in particular enterprises for the production of drinking water has a great importance in today's dynamically developing world.

In Russia, in urgent need of large amounts of fresh water is the Caspian Sea and the Crimea, so the design of industrial plants for desalination of sea water in these areas is an extremely important proposal that can improve a functioning of residential areas.

The importance of such projects for the Crimea is completed by a need of full functioning of its resort component. In particular, in Sudak, which is one of the major resort cities of Crimea, fresh water is supplied for a few hours a day.

\footnotetext{
${ }^{a}$ Corresponding author: timur.gazizow@mail.ru
} 


\section{Station Project on seawater desalination}

The authors offer the Station Project on seawater desalination for the city of Sudak. A district chosen for the station building is optimal for communication with the city because it is located very close to the city and at the same time it is separated from residential areas by a large coastal rock. This arrangement of the industrial object associated with the city's fresh water providing extremely beneficial strategic reasons. At the same time the station has a direct link with runs along the coast highway. The lay of the land allows supply water to the city with minimal use of pumping equipment (Figure 1).

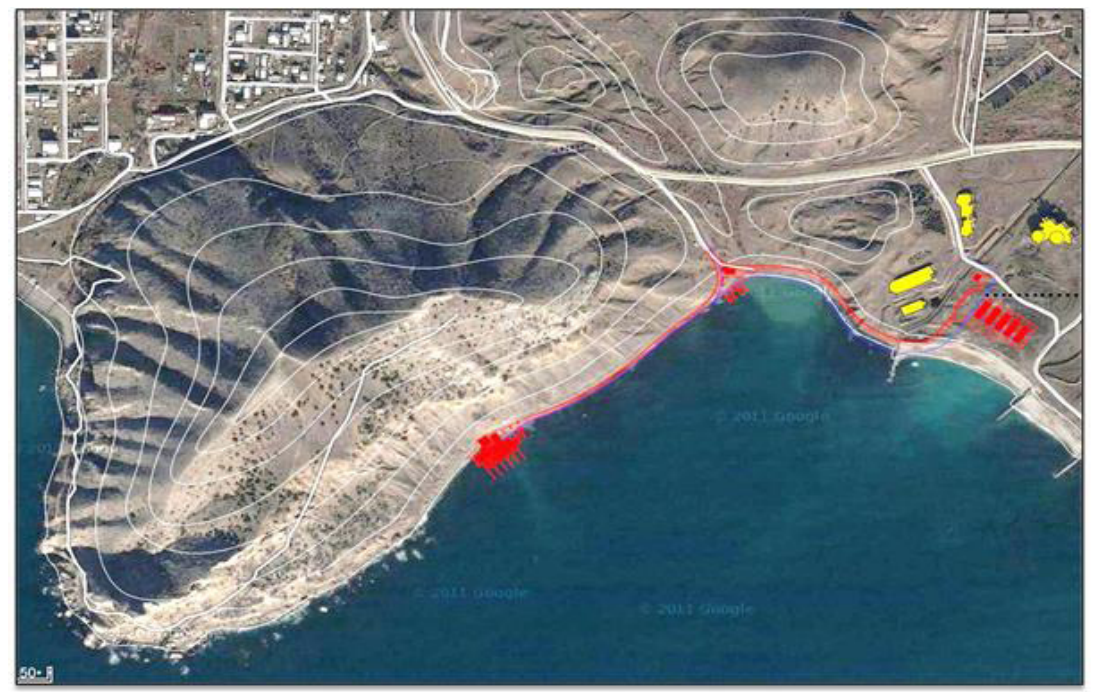

Fig. 1. Situational plan.

Modern methods, technologies and the general trend of development of the technologies for desalination were studied and the most promising of them were identified, namely: the reverse osmosis technology.

By comparison with the long-used "thermal distillation" technology (multi-residue), used since the beginning of the last century, and on which the main emphasis in comparison technology has been made, the technology of "reverse osmosis" (passing sea water through a semipermeable membrane against high pressure) compares favourably with its constructive simplicity, relative cheapness of production and operation.

Reverse osmosis plants is actively used in the world practice the desalination of sea water from the end of the last century. The indisputable advantage of the reverse osmosis method in comparison with its thermal distillation is its small-size, which allows the use of reverse osmosis in the premises of any configuration (Figure 2), 


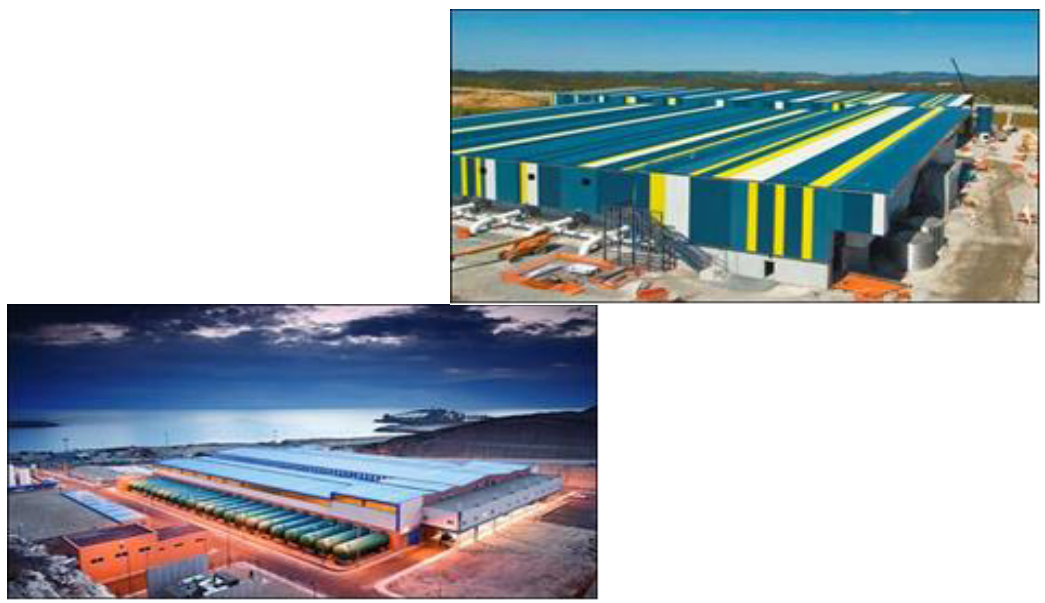

Fig. 2. Examples of reverse osmosis plants of desalination of sea water.

without using of a huge number of hydraulic components, communications, boilers and tanks and other containers, which in the "old technology" was in abundance (Figure 3).

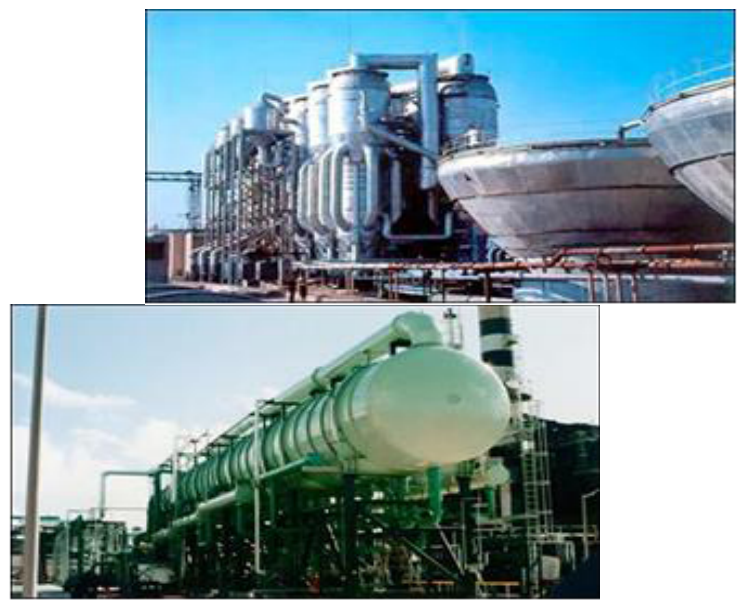

Fig. 3. Examples distillation stations, seawater desalination.

The project involves the design of the station with a complete set of technological operations, shops and facilities needed for a full cycle of desalination of sea water from a water extraction of from the Black Sea its desilting, pre-treatment, ultrafiltration on hollow fibers and disinfection, membrane filtering through the installation of "reverse osmosis", further mineralization and following the fresh water discharge into the existing system of water supply system of Sudak. Perhaps the accumulation of fresh water in the containers located on a coastal area, in the vicinity of the station, and further transportation of fresh water main pipeline to the areas with poor own water resources. For example, an end of a holiday season. The Project provides solution to the problem of waste removal "brine" from the station, namely its multi-stage drying and further use of the resulting dry mixture in various industries, such as fertilizer. The project also provides for the availability an alternate supply, capable of providing a work station in emergency situations without a prolonged power (Figure 4) [1]. 


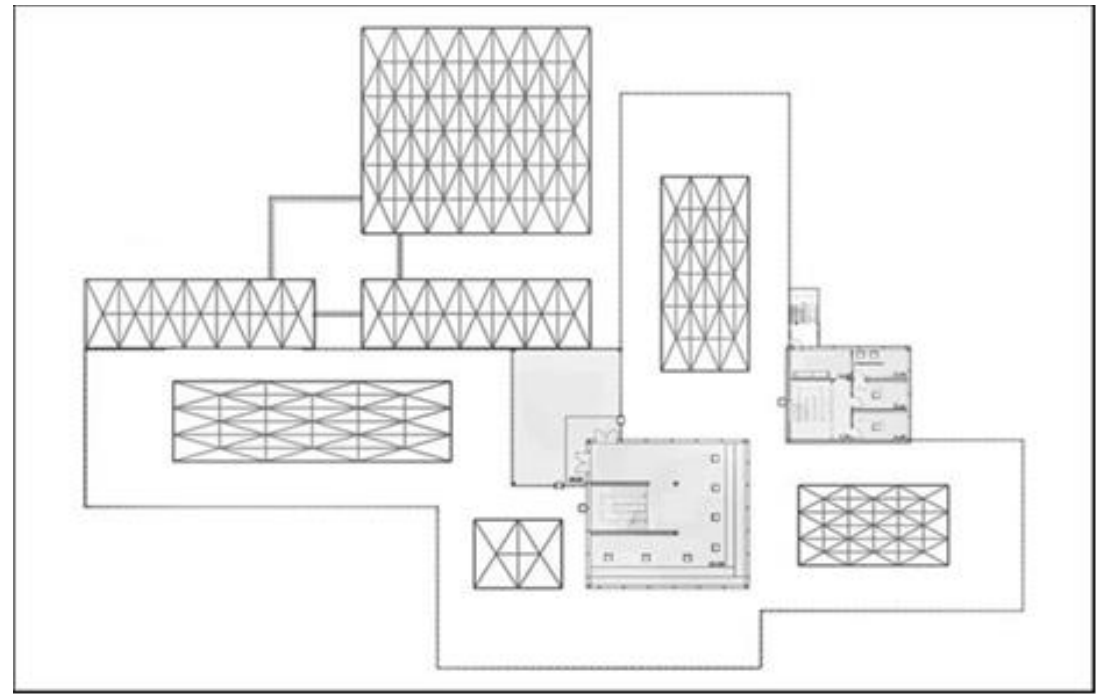

Fig. 4. Plan of the 3rd floor of the station to the placement of solar modules.

Choice planning solutions station based on the specific process for desalination of sea water by the method "Reverse Osmosis" (the transmission of sea water through a semipermeable membrane under high pressure), and the possibility of placing alternative sources of supply in the body of this industrial facility, namely, distribution of polycrystalline solar modules of the third generation (Figure 5).

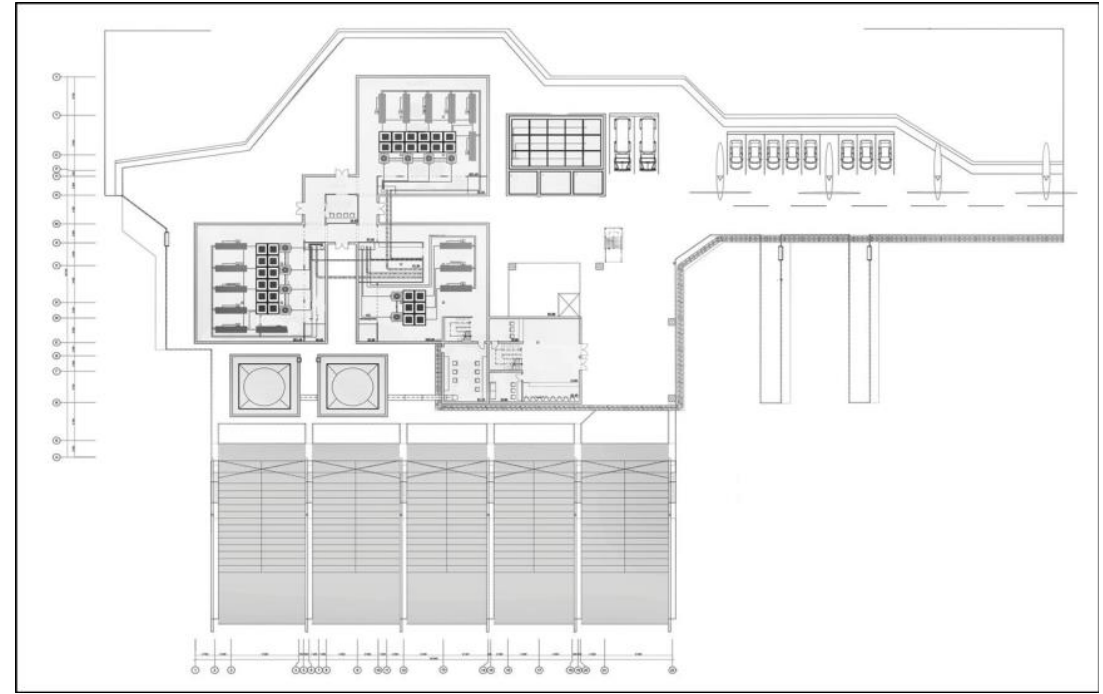

Fig. 5. The plan of the 1 st floor of the station.

Climatic conditions of the Crimea make it possible to use solar panels is very effective even without any preliminary calculation. Shop organization for manufacture of the stations complemented by the development of administration and accommodation unit, combining the current level of control station and the comfortable stay for the working personnel. This unit has a convenient functional connection with the shops, and at the same time it is located on the side entrance to the station. The need of walking any visitors who came to the station administration, excluded from its territory. The station building was designed 
taking into account the partial bearing on the seabed and the coast rocky slope of the shoreline (Figure 6).

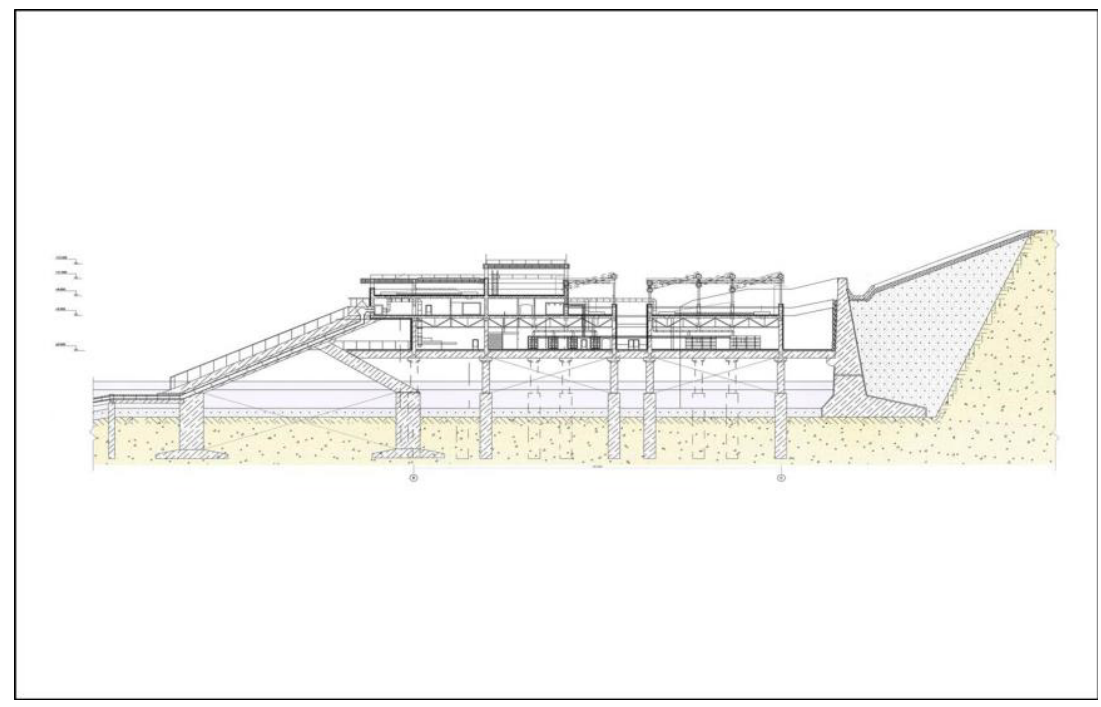

Fig. 6. Constructive section of the station.

The structural building system involves the use of reinforced concrete structures bearing elements of walls and ceilings, using metal trusses at overlapping large spans the shop of the station, installation of foundations using "compressed-air sinking" technology, availability turns off the links and other measures when designing in the area having a high seismic activity. There was also offered the option of using non-metallic reinforcement in concrete structures bearing plant [2]. The roof design involves the installation of rotary polycrystalline silicon third-generation modules with an efficiency of $14-16 \%$, with a total area 920 sq.m., allowing for maximum use of solar radiation energy of about 1350 $1500 \mathrm{Vat} / \mathrm{sq} . \mathrm{m}$., coming to the surface of the station roof. Such a choice of solar modules provides to the station to $14 \%$ efficient power of her work - "in a conservation of energy mode." Also at the territory object have been installed wind turbines that allow to a total of about $8 \%$ efficient power needed for desalination plants [3]. According to our calculations, in the absence of electricity, residents and vacationers of the city of Sudak can be provided with fresh water in a volume of 10 liters/day per person, and it is during a station work alone alternative sources of energy in the height of the season.

\section{Conclusion}

The use of energy-efficient systems in the structure of industrial projects in these conditions is not just effective measure, but it is extremely necessary because they provide significant energy-intensive enterprises with cheap renewable energy resources. As already mentioned, such a system at the industrial enterprises of strategic importance, in particular, associated with fresh water obtaining, can be indispensable in emergency situations, in the event of terrorist attacks and natural disasters (Figure 7), (Figure 8). This variant can be an universal solution in the design of such construction in places where building directly on the coastal territory of the land is impossible. 


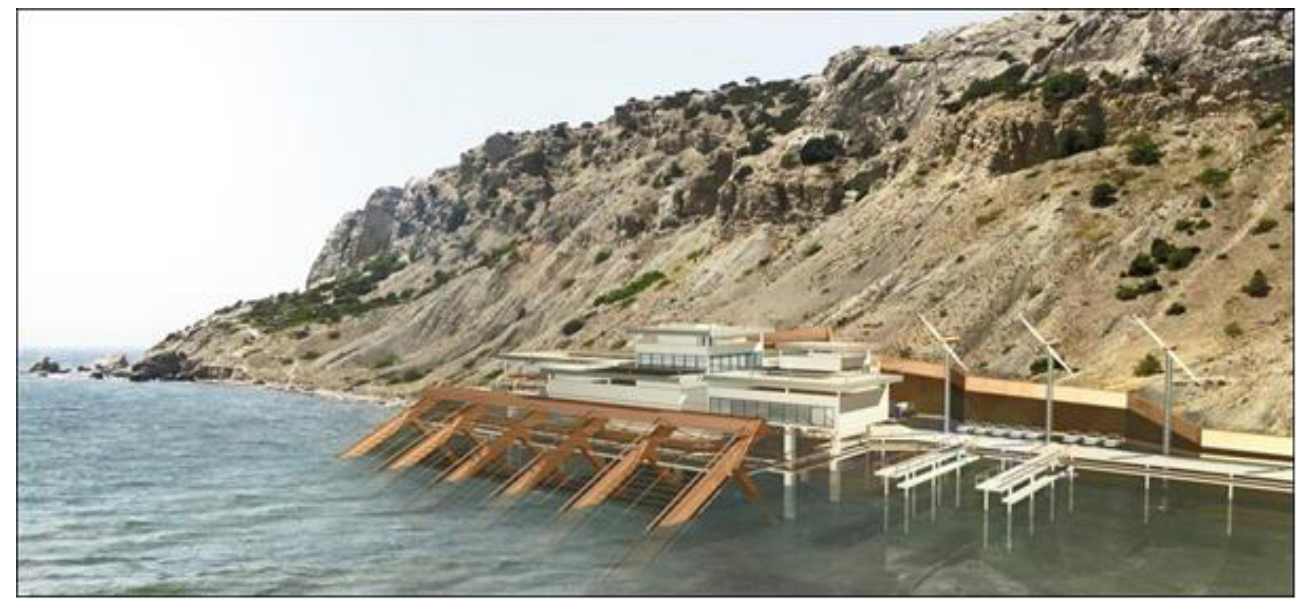

Fig. 7. General view from the north-west side of the station.

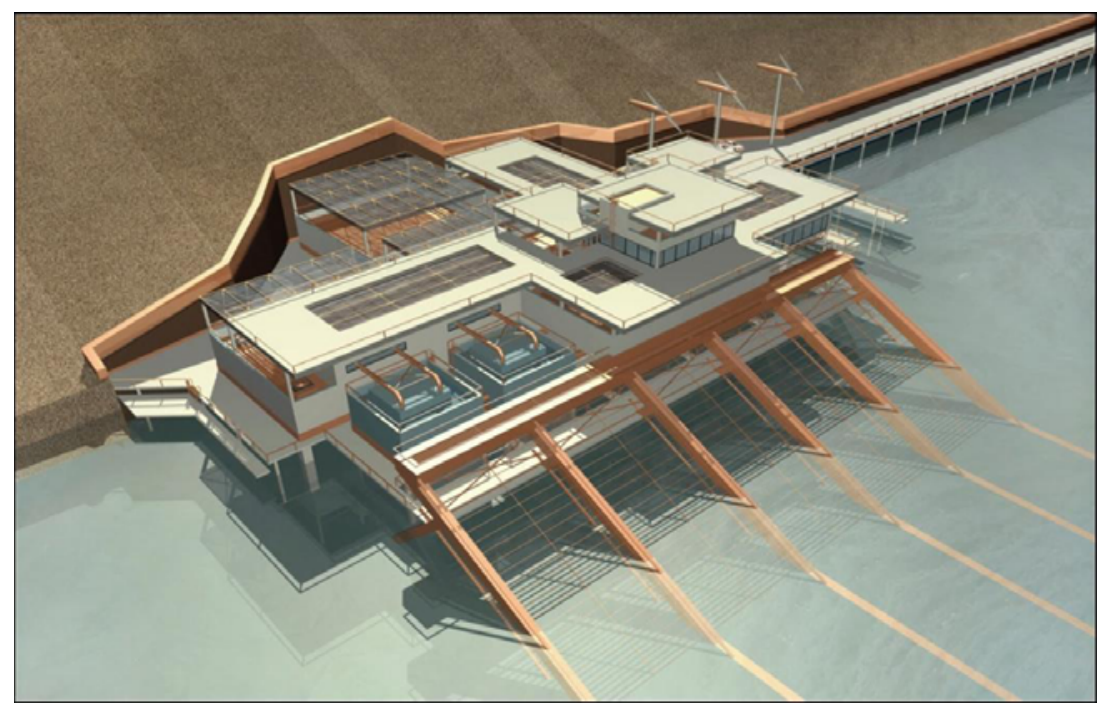

Fig. 8. General view from the south-east side of the station.

\section{References}

1. V.N. Slesarenko, Desalination of sea water (1991)

2. S.V. Dyatkov, A.P. Mikheyev, The Architecture of Industrial Buildings: the textbook for high schools (2008)

3. V. Germanovich, A. Turilin, Alternate sources of energy, Practical design for the use of wind, solar (2011) 